\title{
A QUÍMICA DOS POVOS INDÍGENAS DA AMÉRICA DO SUL
}

\author{
Jens Soentgen ${ }^{\mathrm{a}}$ e Klaus Hilbert $\mathrm{t}^{\mathrm{b}, *, \#}$ \\ ${ }^{a}$ Wissenschaftszentrum Umwelt, Universität Augsburg, D-86159 Augsburg - Alemanha \\ bEscola de Humanidades, Pontifícia Universidade Católica-RS, 90.619-900 Porto Alegre - RS, Brasil
}

Recebido em 01/04/2016; aceito em 27/06/2016; publicado na web em 16/08/2016

\begin{abstract}
THE CHEMISTRY OF INDIGENOUS PEOPLE OF SOUTHAMERICA. The contribution of non-European cultures to science and technology, primarily to chemistry, has gained very little attentions until now. Especially the high technological intelligence and inventiveness of South American native populations shall be put into a different light by our contribution. The purpose of this essay is to show that mainly in the area of chemical practices the indigenous competence was considerable and has led to inventions profitable nowadays to millions of people in the western world and especially to the pharmacy corporations. We would like to illustrate this assumption by giving some examples of chemical practices of transformation of substances, mainly those unknown in the Old World. The indigenous capacity to gain and to transform substances shall be shown here by the manufacture of poisons, such as curare or the extraction of toxic substances of plants, like during the fabrication of manioc flower. We shall mention as well other processes of multi-stage transformations and the discovery and the use of highly effective natural substances by Amazonian native populations, such as, for example, rubber, ichthyotoxic substances or psychoactive drugs.
\end{abstract}

Keywords: Amazonia; indigenous knowledge; pre-Columbian technology.

\section{INTRODUÇÃO}

Neste ensaio, ${ }^{1}$ pretendemos mostrar que, no que concerne ao conhecimento relativo às práticas químicas, a criatividade e a inteligência técnica dos povos indígenas da América do Sul, são competências consideráveis até os dias de hoje. Os povos ameríndios, em especial os da bacia amazônica, desenvolveram práticas que levaram a invenções das quais, até hoje, milhões de pessoas se beneficiam.

A história da química, assim como a história da ciência e da tecnologia em geral, ainda reluta em reconhecer devidamente as contribuições das culturas extraeuropeias. É verdade que o historiador Hermann Kopp permitiu-se, no primeiro volume de sua história da química, falar brevemente dos egípcios e dos fenícios, afirmando de maneira geral que "a química científica [...] se correlaciona estreitamente com o conhecimento empírico, baseando-se por demais nele, para que pudéssemos ignorar inteiramente épocas em que fatos que fazem parte da sua esfera já fossem conhecidos, embora não se pensasse ainda na relação desses fatos por um elo intelectual". ${ }^{2}$

Nesta avaliação, fica inequivocamente claro que as práticas químicas de transformação de substâncias mais desenvolvidas também são um tema que compõem a história da ciência, não restringindo-se apenas ao campo da teoria. Estas práticas também são expostas em obras sobre a história da química, mas fundamentalmente a partir de um enfoque eurocêntrico. Uma exposição mais detalhada das contribuições de culturas extraeuropeias continua sendo, até hoje, a exceção. Somente a contribuição da China e da Índia para o desenvolvimento da ciência e da técnica, e particularmente da química, está presente no senso comum graças às obras monumentais de Joseph Needham e seus seguidores (Science and Civilization in China, ${ }^{3}$ especialmente o volume 5, dedicado à Química) ou de Praphulla Chandra Ray ( $A$ History of Hindu Chemistry; ${ }^{4}$ cf. também Pratik Chakraborty, 2000). ${ }^{5}$

A partir disso, os povos indígenas da América do Sul não parecem ter contribuído para a química e a tecnologia moderna. Em contraponto, existem algumas referências e observações feitas por

*e-mail: hilbert@pucrs.br

"Programa de pós-graduação em História cronistas e viajantes do período colonial a respeito da transformação, manipulação e uso de substâncias que exigem certo conhecimento químico como, ${ }^{6}$ por exemplo: as bebidas fermentadas, os corantes (pau-brasil, urucum), e os venenos (curare e timbó). Mesmo assim, estas populações acabam sendo identificadas como "selvagens primitivos" que ainda necessitam de amparo da civilização moderna para que possam desenvolver-se.

No senso comum, a imagem dos indígenas norte-americanos é marcada pelos filmes de faroeste. E os da América do Sul?

Foi difundida durante muito tempo a imagem que o soldado e aventureiro alemão Hans Staden construiu a respeito dos índios em seu livro: "História verdadeira e descrição de uma terra de canibais selvagens, nus e cruéis, comedores de Seres Humanos, situada no Novo Mundo da América". ${ }^{7}$ Por volta do ano de 1552, Staden se tornou, nas proximidades da atual Ubatuba-SP, ${ }^{8}$ na costa brasileira, cativo dos Tupinambá. Ele, que entendia e falava a lingua Tupi, permaneceu nove meses cativo dos indígenas e só deixou de ser devorado graças a uma mescla de audácia, talento dramático e sorte. Seu livro sobre suas aventuras no Brasil foi publicado em 1557. Devido à sua interessante narrativa, caracterizada pela grande precisão descritiva, ele é, ainda hoje, uma importante fonte de pesquisa sobre o Brasil colonial. Assim como para os seus contemporâneos, a antropofagia e os rituais ligados a ela foram as práticas tupinambá que mais chamaram a atenção do soldado alemão, que os priorizou em seu relato em detalhadas descrições. Entretanto, o livro de Staden também descreve - o que não é reconhecido com tanta frequência -, com o olhar treinado de um especialista no assunto, as tecnologias de seus captores, a preparação de sua bebida fermentada, seus métodos de caça e o seu modo de cultivar a terra.

Portanto, o olhar que Staden lançou sobre os indígenas era mais multifacetado do que poderia parecer inicialmente. O que permaneceu no imaginário coletivo, contudo, foi a figura do canibal ${ }^{9}$ que ele moldou incisivamente, como podemos verificar na Figura 1. Além disso, as respectivas ilustrações produzidas por Theodor de Bry - que nunca esteve na América, mas tomou as descrições de Hans Staden como base para a realização de suas gravuras - são, até hoje, modelos para uma imagem dos "canibais selvagens, nus e ferozes". 


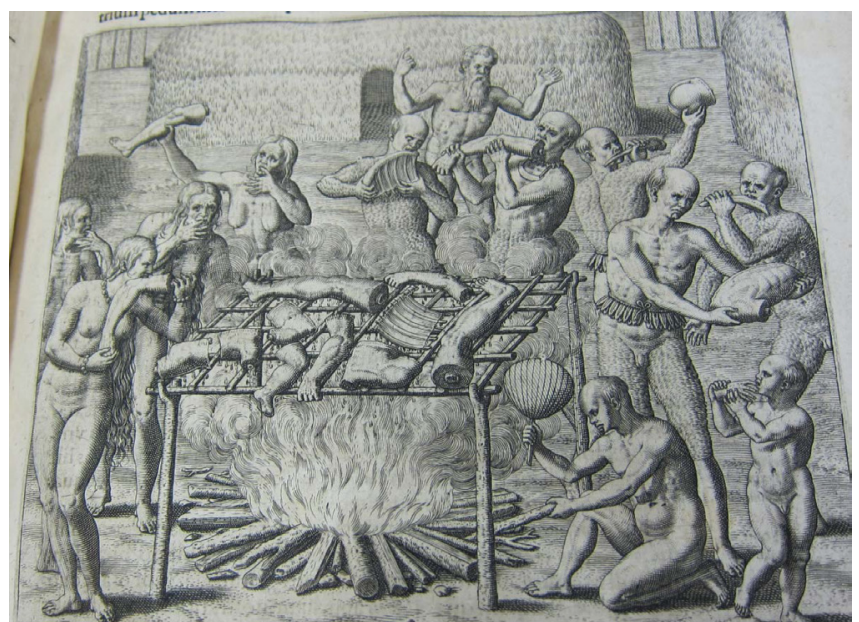

Figura 1. Gravura mostrando um ritual antropofágico entre os Tupinambá presenciado e descrito por Hans Staden. (Gravura de Theodor de Bry, 1593)

Obviamente, esta imagem é tendenciosamente unilateral. Isto porque ela simplesmente ignora o fato de que os indígenas sul-americanos, embora ágrafos, possuíam - e ainda possuem - uma inventividade extraordinária não apenas em relação à formulação de um pensamento cosmológico, mas também no que diz respeito à produção de experimentos tecnológicos.

Especialmente no âmbito das práticas químicas, a competência dos indígenas é considerável e levou a invenções e descobertas das quais, até hoje, alguns milhões de pessoas no mundo ocidental se beneficiam, bem como os funcionários e proprietários de numerosas empresas - particularmente também empresas farmaceuticas alemãs, como Boehringer Ingelheim, Lanxess ou Merck.

Este ensaio é uma tentativa de evidenciar a proeminente capacidade tecnológica dos indígenas amazônicos que permanecem sendo equivocadamente considerados pelo senso comum como "povos primitivos". Os povos indígenas da Amazônia não devem ser excluídos do processo de desenvolvimento científico europeu moderno.

Na Alemanha, por exemplo, é muito comum identificar Alexander von Humboldt como o "verdadeiro" descobridor da América, devido às sofisticadas descrições que produziu sobre a natureza do continente em contraposição aos "descobridores" espanhóis, portugueses ou ingleses, que pouco preocuparam-se em descrever tecnicamente a paisagem e os seres americanos. Aqui cabe salientar que Alexander von Humboldt observou e descreveu minuciosamente a natureza e as populações indígenas apenas na bacia amazônica da América espanhola; entre o Orinoco e o canal do Casiquiare, pois as autoridades portuguesas nunca permitiram ao cientista alemão realizar sua tão desejada viagem pelo rio Amazonas. ${ }^{10}$ Contudo, sem diminuir os feitos de Humboldt, deve-se lembrar, primeiramente, das realizações elaboradas pelos próprios indígenas, cujo conhecimento, além de servir de base para os escritos do naturalista alemão, fundamentavam-se em uma vasta e mais pormenorizada compreensão do ambiente em que viviam, fazendo-os beneficiarem-se dos elementos naturais por meio de extraordinários processos técnicos ${ }^{11}$ - rendendo-lhes criações, inclusive, na área da bioquímica, como mostraremos adiante.

Gostaríamos de documentar essas afirmações com alguns exemplos, limitando-nos a apresentar apenas produtos feitos a partir de substâncias que eram inteiramente desconhecidos na Europa. Portanto, não abordaremos os processos de criação e fabricação de cerâmica, ${ }^{12}$ de cerveja, etc. - ainda que sejam práticas igualmente extraordinárias. Concentramo-nos geograficamente na região amazônica devido à grande quantidade de grupos indígenas que a habitam, permitindo, assim, uma maior variedade de exemplos - contradizendo a ideia de que este seria um lugar em que não nos depararíamos com conhecimentos químicos relevantes.

\section{AMAZÔNIA}

A bacia do rio Amazonas ocupa um papel central em quase todas as questões ambientais em nível global, contando com cerca de 7 milhões de $\mathrm{km}^{2}$ - território comparável ao dos EUA (9,6 milhões de $\mathrm{km}^{2}$ ). As árvores da região amazônica armazenam cerca de 90 a 140 bilhões de toneladas de carbono, o que corresponde a cerca de 90 a 140 anos da liberação média de carbono para a atmosfera pelos seres humanos. ${ }^{13}$

Mas a Amazônia também tem uma importância mundial especialmente por sua singular biodiversidade: as florestas tropicais são reconhecidamente os expoentes da diversidade global de espécies, e, dentre elas, a floresta amazônica é a maior área de mata tropical contínua da Terra - inclusive, superando em extensão as do Congo e da Nova Guiné juntas. Dois terços da Amazônia pertencem ao Brasil, elevando-o ao status de primeira nação do mundo no tocante à biodiversidade.

A Amazônia é o habitat de um quinto de todas as espécies de mamíferos, peixes, aves e árvores do mundo. Ela dispõe de uma abundância singular de angiospermas e, correspondentemente, também de insetos. Uma única cifra pode ilustrar a sua diversidade de espécies: enquanto as matas da Inglaterra abrigam exatamente 12 espécies de árvores, em uma superfície da floresta tropical amazônica do tamanho da Inglaterra podem-se contar cerca de mil espécies de árvores. ${ }^{14} \mathrm{Em}$ função da coevolução de plantas floríferas e insetos, essa riqueza biológica também acarreta uma variedade enorme - praticamente não pesquisada - de metabolitos secundários, pois as plantas produzem venenos principalmente para manter insetos à distância. Quanto mais espécies de plantas e quanto mais espécies de insetos, maior será a multiplicidade de substâncias naturais complexas e ativas. ${ }^{15} \mathrm{~A}$ diversidade bioquímica da Amazônia está diretamente relacionada com a diversidade biológica.

A Amazônia também é o habitat de cerca de 170 povos indígenas e abriga, além disso, 357 quilombos, em que vivem descendentes de ex-escravos. Ela tem, portanto, além da diversidade biológica e bioquímica, também uma extraordinária diversidade étnico-cultural. ${ }^{16}$

É muito provável que a Amazônia só tenha sido povoada no final da última Era Glacial por grupos de caçadores e coletores que migraram para o continente americano passando pelo Estreito de Bering. ${ }^{17}$ Nos últimos 10 mil anos, a região amazônica esteve sujeita a diversas e enormes transformações. Assim, por exemplo, a densidade da vegetação e a profundidade dos rios alteraram-se significativamente com o passar dos séculos. Por causa de processos de sedimentação e erosão do rio Amazonas e de seus afluentes, que tiveram início mais tarde no período do Holoceno, os mais antigos sítios arqueológicos foram soterrados e, por isso, são de difícil localização para os arqueólogos. ${ }^{18}$

Eventualmente, pontas de projéteis desses primeiros imigrantes são encontradas por garimpeiros de ouro, diamante ou cassiterita em suas bateias e, em circunstâncias favoráveis que impedem o comércio ou o desaparecimento destes artefatos, acabam chegando às coleções dos museus públicos. Uma grande quantidade de informações sobre os primeiros habitantes da Amazônia foi fornecida por escavações feitas em cavernas. Assim, em investigações realizadas na Caverna da Pedra Pintada, ${ }^{19}$ em Monte Alegre, e na Gruta do Gavião, na Serra do Carajás foram encontrados, além de artefatos feitos de fragmentos retocados de quartzo que serviam para processar peles, trinchar a caça e cortar fibras vegetais, também encontraram-se ossos, restos de alimantação de origem animal e partes de plantas carbonizadas, como sementes, caules e resinas, que indicam uma ampla utilização dos recursos existentes no final do Pleistoceno (12500 anos atrás). 
Desde aquele primeiro povoamento, as pessoas se confrontavam com a natureza da floresta tropical, usavam as plantas como matérias-primas, alimentos, remédios ou estimulantes. Investigações feitas por Gustavo Politis, ${ }^{20}$ com a ajuda dos índios Nukak ou Makú na região fronteiriça da Amazônia entre a Colômbia e o Brasil, mostram que a utilização dos recursos naturais disponíveis por parte dos primeiros caçadores e coletores também poderia ter influenciado duradouramente seu entorno.

Assim, pôde-se mostrar que em função das atividades de coleta dos Nukak (ou Makú), principalmente de frutos de pupunha (Bactris gasipaes), surgiram paisagens que se assemelham a verdadeiros pequenos pomares. A maior concentração de recursos gerada por fatores antropogênicos define não só o comportamento desses próprios indígenas, mas influencia também o ritmo de vida da fauna local, que, por causa da oferta abundante de alimento, é literalmente atraída para esses pomares de palmeiras. Macacos e javalis, por exemplo, ao procurarem estes lugares de modo deliberado e regular, acabam tirando mais proveito de seus recursos do que os próprios índios Nukak. ${ }^{21}$

\section{E A QUÍMICA?}

A Amazônia, principalmente a região da várzea, é uma região praticamente ausente de rochas e de minerais próximos à superfície. Devido a isto, o manejo de materiais inorgânicos foi menos desenvolvido pelas populações amazônicas se comparado ao alto desempenho que demonstravam, e ainda demonstram, em relação aos usos que dão às matérias orgânicas.

Note-se que não pretendemos demonstrar que os indígenas amazônicos tenham desenvolvido uma teoria química desconhecida até agora. O que pretendemos, isto sim, é demonstrar, a partir de dois exemplos, que eles desenvolveram processos bioquímicos de transformação de substâncias - "conhecimentos químicos", nos termos de Hermann Kopp ${ }^{2}$ - que têm importância central ainda hoje. Trata-se, portanto, de capacidades de obter substâncias por meio de um acurado conhecimento dos materiais orgânicos existentes no território e transformá-las deliberadamente.

Porém, devemos nos questionar se é correto chamar este conjunto de conhecimentos indígenas pelo mesmo termo que nossa sociedade identifica como sendo química, já que este conceito parece restringir-se à prática cientificamente acadêmica de lidar com as substâncias. Pode-se, afinal, estender à Amazônia categorias de formulação eurocêntrica como "química", "substância" ou "metodologia científica"? Isso tem a ver com uma questão muito discutida na historiografia, na etnologia e na filosofia. A historiadora da química Ursula Klein mostrou, em várias publicações, que é extremamente problemático supor que os alquimistas medievais, os "químicos" do século 18 e os químicos dos séculos 19 e 20 quisessem dizer a mesma coisa ao se referirem a uma determinada substância. A ideia de que os objetos possuam um sentido inato e independentemente de determinadas formas de acesso está equivocada. Dever-se-ia, em vez disso, partir de uma ontologia histórica. ${ }^{22}$

Aplicando isto à questão que nos ocupa aqui, pode-se perguntar se, afinal, é adequado designar o que os indígenas fazem como sendo uma metodologia científica de "lidar com substâncias" ou mesmo "química”. Está claro também para nós que essas designações são insuficientes. Por outro lado, como mostrou um dos autores deste texto, a categoria "substância" é efetivamente um termo fundamental para a codificação do mundo e que está tão estreitamente ligada a necessidades concretas que é sensato supor que as pessoas distinguem o termo "substâncias" do termo "coisas", além de compreenderem diferenças internas entre "espécies de substâncias". ${ }^{23}$ Além disso, fica claro que só se precisaria ampliar um pouco o argumento de Ursula Klein a respeito de uma ontologia histórica para, então, excluir a possibilidade de conhecimento histórico (ou etnológico) de modo geral. Parece-nos, não obstante as fragilidades existentes neste enfoque, que o seu ponto forte é a possibilidade de se estabelecerem comparações entre as práticas técnicas adotadas pelos diversos povos, abrindo novas perspectivas de compreensão, que não seriam possíveis caso insistíssemos em uma visão evolucionista, que identificaria as práticas indígenas como a expressão de caráter fetichista, anulando-as enquanto conhecimento, ou uma análise relativista, que, ao priorizar o "provincialismo"24, acabaria por conduzir à incomparabilidade. Como veremos, observadores preocupados em entender as práticas de transformação de substâncias realizadas pelos indígenas enquanto saberes resultantes de técnicas, métodos e experimentalismos singulares julgaram plausível sua comparação com a química.

Que processos poderiam ser estes? A flecha envenenada com curare dos indígenas é conhecida, não só entre químicos. Vamos tratar primeiramente dela.

\section{A arte do envenenamento: curare}

Curare é um termo coletivo para designar venenos para flechas que os indígenas das áreas da bacia hidrográfica do Orinoco e Amazonas obtêm, na maioria das vezes, a partir das cascas de certas espécies de cipós (Strychnos spp.) (Figura 2). A utilização de flechas envenenadas, provavelmente de curare, é mencionada pela primeira vez por Pedro Mártir de Anglería ${ }^{25}$ no ano de 1530 . O cronista e médico da corte espanhola, nascido em Milão, relata que, em 1502, durante a quarta viagem de Colombo à América, que levou os descobridores à costa de Honduras e da Costa Rica, um dos soldados foi ferido por uma flecha envenenada e acabou morrendo. Pedro Mártir não menciona outros detalhes, pois não foi testemunha ocular direta, apenas registrando e transmitindo narrativas de outros.

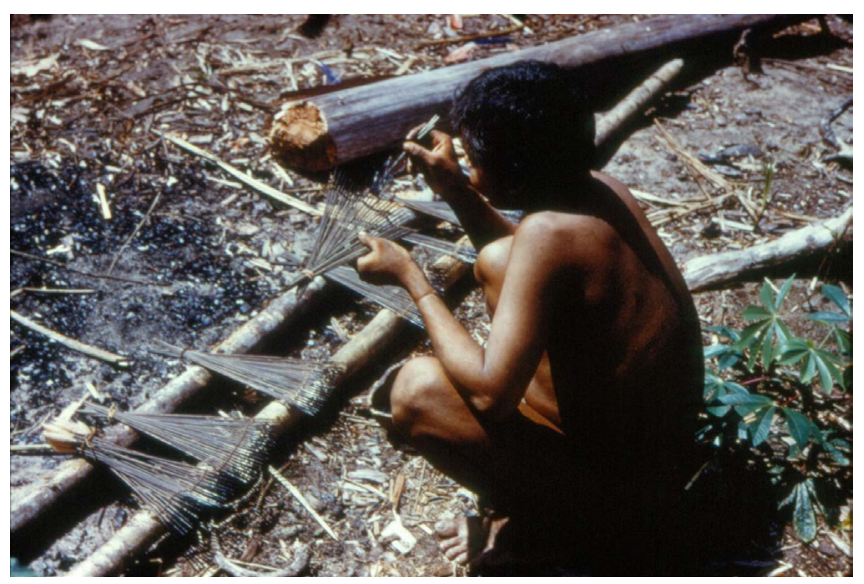

Figura 2. Homem Nukak (Makú) aplicando veneno (curare) nos dardos feitos das fibras duras e flexíveis da palmeira - pupunha. (Foto: H. Schultz, 1960, propriedade do autor)

Diferente é a situação do relato de Gaspar de Carvajal sobre as consequências letais do veneno de flecha entre os indígenas do baixo Amazonas. ${ }^{26} \mathrm{O}$ monge dominicano, que participara da navegação do Amazonas de Francisco de Orellana, fez parte de uma expedição dirigida por Gonzalo Pizarro - irmão de Francisco Pizarro -, que tinha partido de Quito em 1541 para procurar especiarias, ouro e o lendário "Eldorado" na planície baixa de mata tropical, ainda desconhecida, que ficava do outro lado dos Andes. O enorme desgaste durante a travessia dos Andes e das pantanosas estepes altas e as confrontações bélicas com os indígenas fizeram com que essa tropa, que no início tinha cerca de 3 mil homens, sofresse muitas baixas. Em pouco tempo, as reservas de alimentos também ficaram escassas, 
de modo que, na cabeceira do Rio Napo, Francisco de Orellana foi enviado para conseguir víveres. Após esperar em vão o seu retorno, Gonzalo Pizarro resolveu prosseguir com a expedição descendo o rio Amazonas em um bergantim de fabricação própria junto com um pequeno grupo de mercenários espanhóis e alguns indígenas, já que contornar os caudalosos rios das montanhas lhe pareceu impossível. Os espanhóis, que estavam sempre em busca de mantimentos, tentaram atracar na proximidade da atual cidade de Santarém, situada na foz do Rio Tapajós, no baixo Amazonas. Lá eles se depararam com um grande número de indígenas que os atacaram e, sob o barulho de trombetas e gritos de guerra, expulsaram os invasores. Dois dos espanhóis foram atingidos por flechas envenenadas e morreram sob muita dor (Figura 3). Gaspar de Carvajal relata, em suas descrições de viagem, que entre os indígenas também havia algumas mulheres com cabelo comprido que se destacaram por uma particular selvageria e ousadia, comparando-as com as amazonas da mitologia grega. $\mathrm{O}$ nome do rio se baseia nessa passagem fantástica do relato da viagem: o atual nome "Amazonas" deriva da expressão original "Rio das Amazonas".

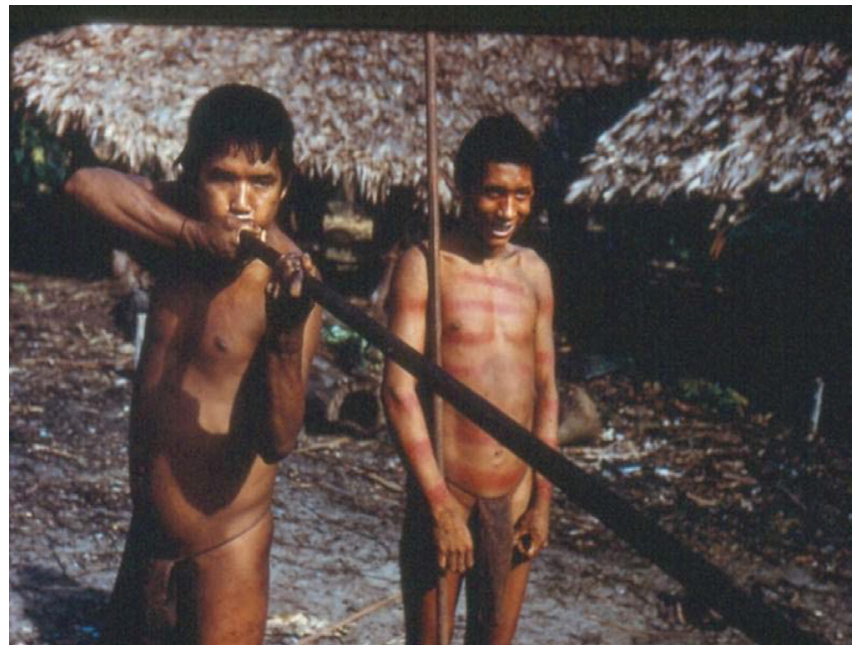

Figura 3. Índio Nukak (Makú) com sarabatana e dardos envenenados com curare. (Foto: H. Schultz, 1960, propriedade do autor)

Dos numerosos relatos existentes sobre a preparação do curare, ${ }^{27}$ o registrado por Alexander von Humboldt em seu famoso relato de viagem parece-nos o mais ilustrativo:

Tivemos a sorte de encontrar um indígena idoso que estava menos embriagado do que os outros e ocupado com a preparação de curare a partir das plantas recém-coletadas. Ele era o químico (chimiste) do local. Encontramos com ele grandes caldeiras feitas de barro para cozinhar a seiva das plantas; vasilhames mais rasos que favoreciam a evaporação por causa da ampla superfície que ofereciam para isso; folhas de banana que, enroladas em forma de sacola, eram usadas para filtrar os líquidos mais ou menos impregnados de fibras. Em toda parte havia a maior ordem e limpeza nessa cabana transformada em laboratório de química (laboratoire de chimie). O indígena que iria nos dar informações é conhecido na missão sob o nome de mestre do veneno (maître de poison, amo del Curare): ele tinha a aparência cerimoniosa e o tom pedante que costumavam ser criticados antigamente nos farmacêuticos da Europa. "Eu sei, disse ele, que os brancos possuem o segredo de fazer sabão, e aquele pó preto que tem a desvantagem de fazer barulho e afugentar os animais quando não se acerta neles. $\mathrm{O}$ curare, que sabemos preparar de pai para filho, é bem melhor do que tudo que vocês conseguem produzir lá (do outro lado dos mares). Ele é a seiva de uma planta que mata bem silenciosamente (sem que se saiba de onde veio o tiro)". ${ }^{28}$

De modo bem consciente, o indígena compara os próprios produtos com famosos produtos químicos dos europeus e afirma que são superiores. Humboldt destaca a semelhança não só da postura, mas também do inventário material na cabana daquele indígena com laboratórios químicos. A descrição do processo de produção do veneno é, essencialmente, um procedimento baseado na evaporação e na filtração em uma temperatura definida. Na sequência, o sumo obtido ainda é engrossado. Humboldt prossegue:

Os ramos do mavacure [uma espécie de cipó, Strychnos guianensis, JS], que têm 4 a 5 linhas [linha = 2-3 mm, JS] de diâmetro, são raspados com uma faca; o córtice tirado é triturado em uma pedra usada para ralar mandioca e dividido em fibras bem finas. Porque o sumo venenoso é amarelo, toda a massa fibrosa adquire essa cor. Ela é jogada em um funil que tem 9 polegadas de altura e 4 de largura [polegada $=2,5 \mathrm{~cm}, \mathrm{JS}]$. Esse funil é, entre todos os equipamentos do laboratório indígena, aquele que o mestre do veneno (maître du poison) mais exaltou para nós. Ele perguntou várias vezes se por allá (lá, ou seja, na Europa) alguma vez tínhamos visto algo que se comparasse a seu embudo. Tratava-se de uma folha de banana enrolada em torno de si mesma em forma de sacola, que era colocada em outra sacola mais forte feita de folhas de palmeira. O mecanismo todo estava assentado em uma armação leve construída com talos e raque de palmeiras. Primeiro se faz uma infusão fria colocando água sobre a massa fibrosa do córtice ralado ou triturado do mavacure. Uma água amarelada escorre em gotas, por várias horas, pelo embudo, o funil de folhas. Esse filtrado é o sumo venenoso, que, porém, só atinge sua potência depois de concentrado, de modo semelhante a melado (melasses), em grandes recipientes de barro por evaporação.

Em seguida, Humboldt e seu acompanhante, Aimé Bonpland, são convidados pelo chefe do laboratório a provar o sumo; a qualidade do veneno é definida com base no amargor da substância. Quando o curare é absorvido pelo trato gastrointestinal, só é moderadamente venenoso - diferente de quando entra em contato direto com o sangue, por exemplo, através de ferimentos, podendo tornar-se letal.

O que chama a atenção na descrição de Humboldt é o fato de ele comparar com naturalidade o indígena com químicos e farmacêuticos; e ele faz isso com razão, pois a técnica utilizada para o preparo da substância requer rigor: o calor para a concentração é aplicado com precisão, e só são utilizadas partes bem específicas da planta que tenham sido piladas previamente. Só assim são conservados os alcaloides essenciais, cuja concentração é verificada provando-se seu gosto. É até possível, como se constatou em uma investigação na década de 1950, que a concentração dos alcaloides ativos seja aumentada pelo processo, o que acontece pela metilação das bases terciárias de nitrogênio, que se transformam em quaternárias. ${ }^{29}$

O curare, uma substância que teria permanecido desconhecida se não fosse produzida pelos povos indígenas da América do Sul, teve uma segunda carreira na Europa. Por distensionar os músculos - o envenenamento com curare provoca a paralisia, que leva à morte -, ele foi usado bastante cedo pela medicina. Primeiro como remédio contra o tétano e depois também como anestésico em operações. Atualmente, os alcaloides ativos das diversas espécies de curare não são mais utilizados em operações para relaxar os músculos. 
Entretanto, o cloreto de alcurônio (alloferine) produzido a partir dessas substâncias por síntese parcial continua sendo usado como relaxante muscular estabilizante.

\section{A arte do desenvenenamento: a mandioca}

Agora gostaríamos de voltar a atenção para o processo oposto, o desenvenenamento. Ainda que não exija técnicas tão sofisticadas quanto a produção de substâncias, o desenvenenamento é um procedimento fundamental para as pessoas que vivem e queiram sobreviver na floresta tropical amazônica, tendo em vista que muitas plantas de lá produzem veneno em virtude de seu metabolismo secundário. Afinal, a forma que muitas espécies de plantas possuem para evitar a mordida de insetos é a produção de recursos químicos defensivos. Quem quer sobreviver na floresta tropical precisa saber como neutralizar ou afastar essas substâncias tóxicas produzidas pelas próprias plantas. O domínio da arte do desenvenenamento é o que possibilita os habitantes da Amazônia a não morrerem de fome.

Nesse sentido, examinaremos o exemplo da raiz de mandioca de maneira mais detalhada para então, na sequência, fazermos referência sumária a outros produtos e processos. A última seção tratará de algumas implicações políticas de nossa perspectiva.

No Brasil, a mandioca (Manihot esculenta) é conhecida sob diversos nomes em diversas regiões. No sul do país, ela também se chama "aipim”, no Brasil central, "maniva”, "manaíba”, "uaipi”, e no norte, "macaxeira" ou "carim".

A mandioca é uma maleiteira (Figura 4). Em seus tubos leitosos, a planta toda contém o glicosídeo de ácido cianídrico linamarina, bem como um pouco de lotaustralina. Estas cindem ácidos prússicos quando o látex dos tubos leitosos é machucado e as linamarases armazenadas nos tecidos restantes se juntam. A ingestão de 200 a 500 gramas de tubérculo fresco já seria letal. Contudo, esta planta é o alimento básico de quase todos os grupos indígenas das terras baixas da América do Sul. E bem mais: atualmente, a mandioca é o alimento básico de mais de 400 milhões de pessoas nos trópicos. A mandioca-brava, mesmo possuindo uma quantidade muito maior de ácido cianídrico que a "mandioca-doce", ainda assim é o alimento preferido das populações indígenas sul-americanas, pois tem um rendimento maior. ${ }^{30}$

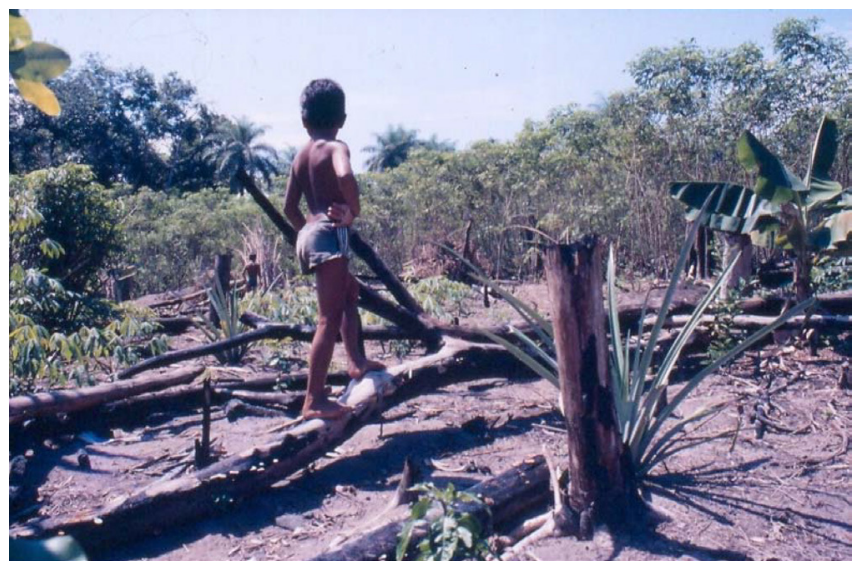

Figura 4. Numa típica roça amazonense apenas os arbustos e as árvores medianas são derrubadas e queimadas antes da estação das chuvas. Nesta roça foram plantadas mandioca, café, abacaxi e bananas (Foto: K. Hilbert, Rio Trombetas 1992)

Mesmo que pareça paradoxal e desminta a nossa própria tradição agrícola, há várias vantagens para as pessoas escolherem plantas altamente tóxicas como alimentos básicos. Para que isso não pareça um absurdo, é preciso explicar um pouco. Nós estamos acostumados a tirar todo veneno de nossas plantas e torná-las tão inócuas quanto possível. Obviamente, isto nos tráz vantagens, principalmente, em relação ao consumo. Em contrapartida, também gera a desvantagem de diminuir consideravelmente, ou até anular inteiramente, os mecanismos de defesa das plantas cultivadas. Nós temos que pulverizar sobre a plantação venenos que têm a função de afastar outros usufrutuários, como os insetos - ou, ironicamente, buscamos reforçar sua imunidade por meio de processos de modificação genética realizados em laboratórios.

Caso nossa sociedade tivesse optado por não alterar a imunidade natural das plantas e as cultivasse assim desde o princípio, os problemas relacionados ao uso de agrotóxicos, fragilidade das folhas e frutos e a contaminação do solo e de lençóis freáticos não teriam chegado aos níveis preocupantes em que se encontram atualmente. Desta forma, os insetos, micro-organismos e os outros animais evitariam as plantas, não havendo grandes prejuízos aos grupos horticultores. Em compensação, os próprios consumidores passariam a ter o problema de desenvenenar o alimento. Analisando-se as populações indígenas, percebe-se que o mais usual é a utilização do cozimento para a eliminação das proteínas venenosas. Porém, outros métodos mais sofisticados também são utilizados para o desenvenenamento, como o uso de substâncias que ligam os venenos por suas grandes superfícies. Assim, como constatou o antropólogo americano Timothy Johns nos Andes, determinadas batatas com forte teor de solanina são desenvenenadas com a ajuda de argilas. ${ }^{31}$

A raiz da mandioca contém glicosídeos cianídricos. Se a planta é machucada por inimigos que a devoram, os glicosídeos cianídricos entram em contato com enzimas especiais da planta e o ácido cianídrico altamente venenoso é liberado. Por causa da toxicidade, a planta, cuja raiz é muito rica em amido nutritivo, tem poucos inimigos. A maioria dos animais e também a maioria dos insetos a deixam em paz.

Entre os povos indígenas da Amazônia são utilizados vários processos com finalidade de desintoxicar a planta para consumi-la sem o perigo de envenenamento (Figura 5). Reproduziremos aqui o procedimento-padrão para o desenvenenamento da mandioca, cujo emprego é o mais difundido na Amazônia. ${ }^{32-34}$ Trata-se de uma combinação sofisticada de práticas que podemos identificar como processos mecânicos, hidráulicos e bioquímicos. Este procedimento transforma um tubérculo altamente tóxico em uma farinha torrada muito nutritiva, que consiste quase totalmente em amido, além de outros subprodutos.

Enquanto que o procedimento de preparação do curare é feito exclusivamente por homens, o desenvenenamento da mandioca é

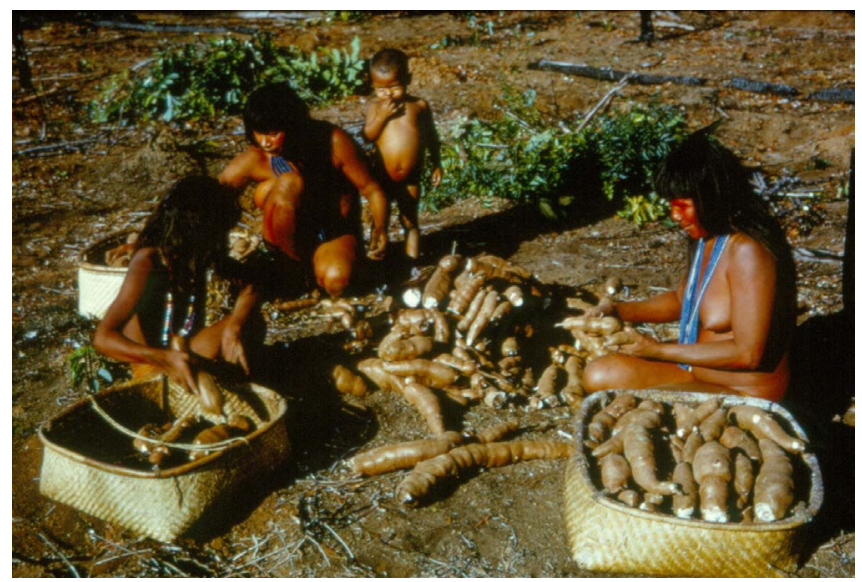

Figura 5. Mulheres Waurá em sua roça. O plantio e a colheita das raízes da mandioca é tarefa das mulheres, bem como seu transporte a aldeia em grandes e pesados cestos. (Foto: H. Schultz, 1960, propriedade do autor) 
tarefa das mulheres. Inicialmente, a raiz da planta é colocada durante a noite ou por alguns dias em um riacho, até que começa uma leve fermentação ácida. Essa fermentação tem diversos efeitos: os micro-organismos ou os produtos de seu metabolismo atacam as paredes dos vacúolos das células em que estão depositados os glicosídeos cianogênicos e possibilitam, assim, que a linamarina entre em contato com a linamarase, de modo que mais ácido cianídrico é liberado. Além disso, por causa dos micro-organismos gerados na fermentação, também se produz linamarase, que decompõe a linamarina, e, além disso, em função do baixo valor do $\mathrm{pH}$, cria-se o ambiente que intensifica a atividade da enzima já existente na planta. ${ }^{35}$ Com a diminuição do valor do $\mathrm{pH}$, o equilíbrio dissociativo do ácido cianídrico é deslocado na direção do ácido cianídrico (HCN), e o ácido cianídrico indissociado é removido do líquido. Após a exposição à água, as cascas do tubérculo devem ser removidas, já que nelas encontra-se uma concentração particularmente elevada dos glicosídeos cianídricos.

Após serem descascadas, as mandiocas são raladas, transformando-se em uma farinha grossa e úmida. ${ }^{32}$ Os raladores indígenas consistem numa tábua grande, levemente abaulada para dentro, em que se colam com uma resina ou algo semelhante muitas pedrinhas pontudas, lascas de madeira ou dentes para produzir fricção. Atualmente, alguns grupos amazônicos, influenciados pelo contato com o homem branco, substituíram esses raladores de madeira por latas de gasolina descartadas em que se fazem, com pregos, buracos com bordas afiadas.

Para a continuação do procedimento de desenvenenamento da mandioca usa-se a famosa prensa tipiti - instrumento produzido pelos indígenas que se assemelha a uma mangueira (Figura 6). O uso do tipiti, ou tepeti, que na língua tupi significa "cesto para espremer água", foi descrito detalhadamente já em 1587 por Gabriel Soares de Sousa $^{36}$ no Tratado descriptivo do Brasil. Theodor Koch Grünberg, que viajou pela Amazônia, descreveu sua utilização, no início do século 20, da seguinte maneira:

Da massa branca [da raiz ralada de mandioca], que se parece com batata ralada, se remove o sumo tóxico, que contém ácido cianídrico, por meio de uma mangueira cilíndrica de palha trançada ou amassando-a longamente em uma peneira fina, colocada sobre uma armação de madeira triangular, dobrável. A mangueira - trançada com tiras de taquara resistentes, mas muito elásticas (tipité) - que foi recheada com a massa, está pendurada em uma viga proeminente da casa e é pressionada por um peso pendurado no anel inferior ou por um sarrafo para fazer pressão sobre o qual às vezes se senta a família toda. Com isso, a mangueira é esticada e espreme o sumo tóxico para fora, que escorre para um recipiente de argila colocado por baixo. ${ }^{37}$

A prensa utilizada exclusivamente para a preparação de mandioca é uma invenção indígena, para a qual não existia paralelo na Europa. Ela parece ter sido desenvolvida pela primeira vez no nordeste da Amazônia. ${ }^{11}$

O sumo que escorre após o prensamento no tipiti e que ainda é tóxico, é reaproveitado de duas maneiras: ou ele é usado para a conservação de carne, ou então é desenvenenado para produção do tucupi. ${ }^{11}$ Para isso, é deixado exposto ao sol por alguns dias, até fermentar, removendo mais um pouco do ácido cianídrico. O resto das toxinas é tirado cozendo-se o líquido, surgindo o sumo ácido chamado tucupi, de cor clara amarelada, que também é empregado na alimentação.

A farinha de mandioca prensada com o tipiti, ainda úmida, geralmente é colocada em uma canoa, o maior recipiente à disposição. $\mathrm{Na}$

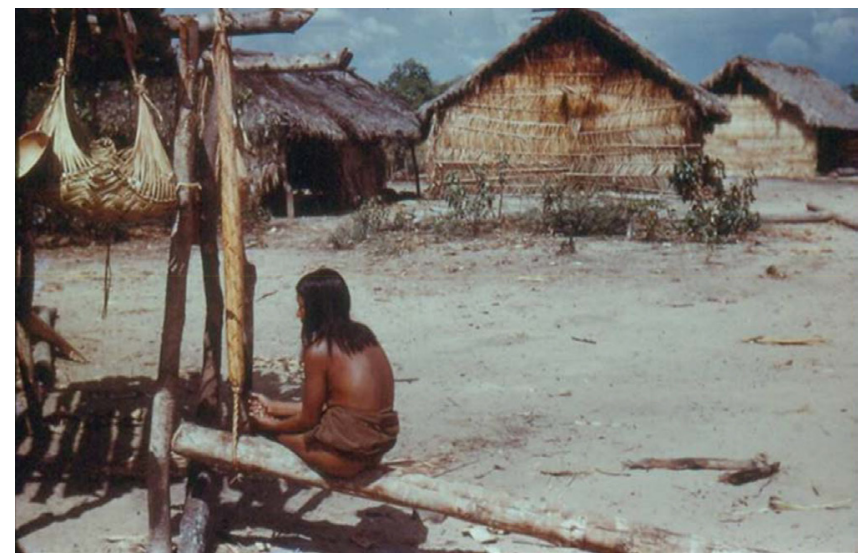

Figura 6. Mulher Krahó sentada num tipiti. A parte superior da prensa, recheada com a massa da mandioca ralada, é enlaçada na cumieira da casa, enquanto que a parte inferior é fixada num tronco sobre qual a mulher está sentada. Com o peso da pessoa, o tipiti, feita de fibras, se estica, a massa da mandioca é comprimida, assim o líquido é extraido e coletado numa cuia. Sobra no tipiti a massa quase seca que, posteriormente, é torrada. No recipiente separa-se o amido (tapioca), do tucupi, um líquido amarelado com forte cheiro de cianeto (Foto: H. Schultz, 1960, propriedade do autor)

sequência, seca-se a farinha em grandes assadeiras sobre o fogo, sendo ela constantemente remexida, como podemos observar na Figura 7, o que faz com que escape o resto de ácido cianídrico.

A farinha obtida pode ser conservada durante meses, e, para a ocasião do consumo, é tostada e tem um ótimo gosto. Come-se farinha de mandioca em toda a Amazônia, acompanhada de peixe, carne ou hortaliças.

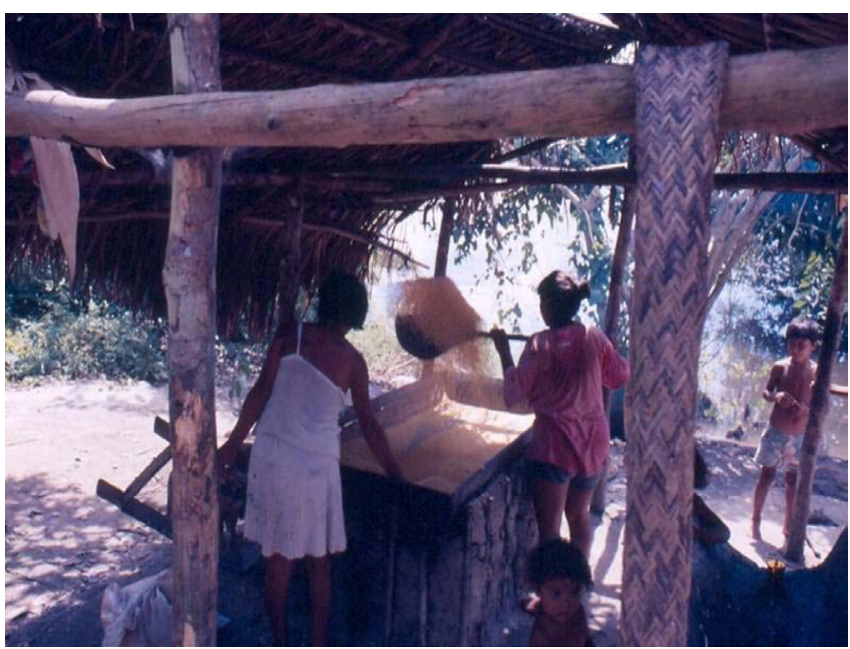

Figura 7. A farinha da mandioca é torrada, na casa de farinha, em grandes fornos de barro. A cabocla usa um remo velho e joga a farinha grossa com muita habilidade no ar, até que ela seja bem seca e crocante. No primeiro plano da imagem ve-se, pendurado de um dos caibros da casa, uma prensa telescópica, o tipiti. (Foto: K. Hilbert, Rio Trombetas 1992)

Os outros subprodutos da mandioca são usados em toda parte na culinária amazônica. Obtém-se o amido quando se deixa o sumo que resta da massa da mandioca parado até que o tucupi tenha se separado da goma, que decanta no fundo do recipiente. O tucupi, depois de ser fervido mais uma vez, é usado de diversas formas na cozinha amazônica. Ele é fortemente temperado com pimenta vermelha ou serve de substância básica para vários tipos de sopas e caldos, em que se cozinha peixe, crustáceo, frango ou carne de pato 
com muitos tipos de hortaliças e, naturalmente, é combinado com farinha de mandioca (Figura 8).

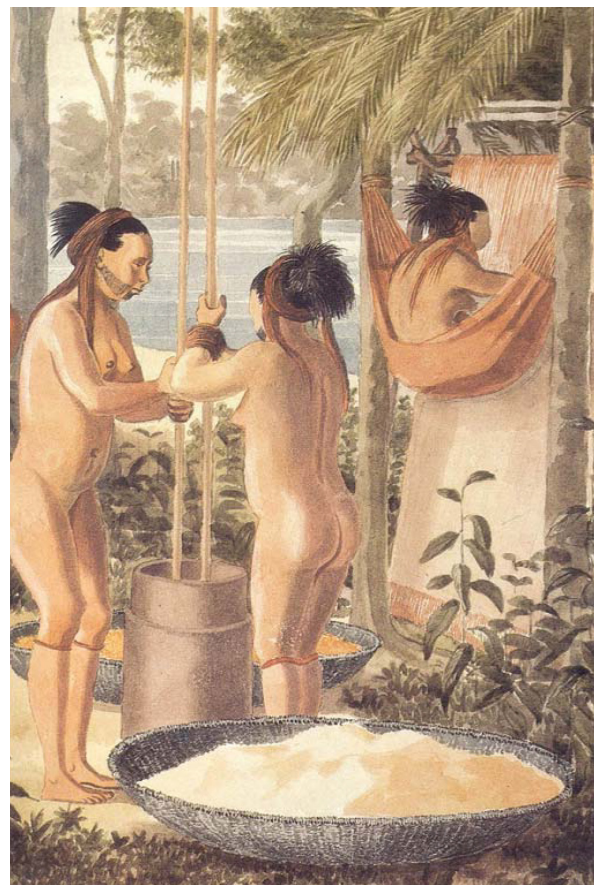

Figura 8. A aquarela de Hercule Florence, que participou como desenhista da expedição G. I. von Langsdorff (1830). Representa um grupo de mulheres Apiaká pilando e peneirando farinha de mandioca

As folhas da planta da mandioca também são usadas na culinária amazônica. Depois de passadas no moedor, elas são vendidas no mercado e usadas para cozinhar uma sopa tradicional, a maniçoba. A preparação da sopa é demorada. As folhas moídas são cozinhadas durante uma semana, quase ininterruptamente, junto com vários tipos de tempero, toucinho, linguiça e carne de porco salgada. A sopa grossa, bastante salgada e com um gosto um tanto rançoso, é servida com farinha e preparada pela população sertaneja principalmente para eventos festivos, como o Natal e no dia comemorativo da santa local, Nossa Senhora de Nazaré. ${ }^{38}$

Os talos da planta da mandioca que sobram são chamados de maniva. Os mais robustos e sadios são usados como estacas para as novas plantas de mandioca. Os talos são cortados em um comprimento de cerca de 30 centímetros, recebem uma ponta em uma das extremidades e são enfiados no solo previamente escavado.

\section{Outras descobertas da Amazônia}

Os procedimentos descritos acima - o desenvenenamento da mandioca e a produção de tucupi - são apenas dois exemplos de muitos outros processos com múltiplas etapas para a transformação deliberada de substâncias que os indígenas da Amazônia desenvolveram. Inúmeras substâncias naturais altamente ativas foram descobertas e usadas por eles. $\mathrm{O}$ arbusto da coca, ${ }^{39,40}$ a quinquina, ${ }^{41,42} \mathrm{o}$ arbusto do jaborandi, que contém o alcaloide pilocarpina, ${ }^{43}$ são apenas alguns exemplos que ilustram a importância destas descobertas para a farmacêutica moderna, que não deveria ignorá-las.

Os indígenas descobriram a seiva do látex, que também existe em plantas europeias, mas que não era usada, passando a ser conhecida pelos europeus após o contato com as populações ameríndias e, daí, sendo possível a fabricação de produtos de borracha, como botas, mangueiras, bolas, etc.; os indígenas amazônicos também são responsáveis pela invenção de uma cerveja que não precisa ser maltada; ${ }^{44}$ seus vizinhos na América Central descobriram que, mediante fermentação, os grãos da árvore do cacau, cujo gosto é insignificante, podem se transformar em uma iguaria na qual toda uma indústria se ocupa atualmente. ${ }^{45}$ Usando carvão vegetal, os indígenas desenvolveram métodos de compostagem que transformam o oxissolo pouco fértil da região amazônica em terras pretas de fertilidade duradoura. As áreas em que se encontram terras pretas indígenas são usadas intensivamente para fins agrícolas, mas o mistério da preparação dessas terras não pôde ser completamente desvendado até hoje, apesar de alguns progressos em sua análise. ${ }^{46}$

O uso de venenos vegetais na pesca é um hábito cultural antigo e bem conhecido em praticamente toda a América do Sul. O timbó - "o que tem a cor branca”, em Tupi - não está relacionado com uma única espécie de planta, mas designa um conjunto de dezenas de espécies de vegetais diferentes. Os princípios ativos dessas plantas são os alcalóides, os taninos, os compostos cianogênicos, a rotenona, os saponáceos, os glucosídios cardíacose e o ictiotereol. São jogados na água pedaços da casca ou as raizes esmagadas de plantas das famílias das leguminosas e das sapindáceas, que possuem uma seiva branca e tóxica. Os peixes envenenados começam a boiar e são facilmente capturados com as mãos. ${ }^{47,48}$

Muitas drogas psicoativas também foram descobertas e usadas pelos indígenas. Em sua Rélation historique, Humboldt descreve um exemplo, bastante ilustrativo:

Eles colhem as vagens compridas de uma planta da família das mimosas que nós descrevemos sob o nome de Acacia niopo [Anadenanthera peregrina, JS]; cortam-na e deixam-na fermentar, umedecida. Quando as sementes amaciadas começam a ficar pretas, eles fazem delas uma massa e, depois de a misturarem com farinha de mandioca e a cal obtida de uma concha de aruá, colocam a massa acima de um fogo vivo sobre uma grelha feita de madeira muito dura. ${ }^{28}$

Essa massa é então pulverizada e cheirada com canudinhos feitos de ossos de aves; ela provoca estados de torpor. ${ }^{49}$ Deve-se salientar o acréscimo de cal, por razões puramente químicas, que depois é queimado com as substâncias ativas vegetais. Essa substância, bastante rara na Amazônia, contribui para liberar a base do alcaloide, de modo semelhante à coca, também proveniente da Amazônia. ${ }^{50}$

Cheirar drogas alucinógenas é algo disseminado no oeste e noroeste da Amazônia, nas duas Guianas, no Caribe, no alto e baixo Amazonas e nas regiões dos Andes. ${ }^{51,52,53}$ A substância básica para a produção de drogas para cheirar é obtida a partir de diversas plantas que contêm alcaloides. A maioria das informações disponíveis é sobre o uso de Anadenanthera peregrina, Mimosa Acacioides ou Piptadenia peregrina. ${ }^{54,55}$ Muitas vezes, também acrescentam-se a estes elementos botânicos básicos substâncias como a cal, a cinza do córtice da árvore de cacau moída (Theobroma subincanum) e, principalmente, o tabaco (Nicotina tabacum), que é amplamente disseminada na Amazônia. ${ }^{56}$

Apesar das particularidades regionais e culturais, os utensílios usados para inalar drogas narcóticas são muito semelhantes. Nos trabalhos de Alexandre Rodrigues Ferreira (1885-1888) é reproduzido um conjunto completo para cheirar drogas, em que se podem ver um almofariz de madeira com pilão para partir as sementes, uma pequena escova, um recipiente para guardar o pó pronto para cheirar - consistindo de uma concha de caracol grande (Strophocheilus sp.) -, uma tábua usada como base para cheirar a droga, um banquinho e vários tipos de canudinhos para a inalação feitos de ossos de animais. Cheira-se usando o osso de ave, um canudo comprido, ou uma folha enrolada. O pó que se pretende inalar é tirado do recipiente e derramado diretamente sobre a palma da mão, sobre uma folha ou uma tábua. As tábuas usadas como base para a inalação dos índios 
Maué e Mura às vezes são ricamente ornadas com madrepérola. Nas pontas, as tábuas são muitas vezes enfeitadas com cobras, jacarés ou símbolos de borboletas. ${ }^{57}$

Apesar da ampla descrição de dados etnográficos a respeito do uso e da produção de drogas inaláveis na região amazônica, as evidências arqueológicas são bastante escassas. Isto provavelmente decorre devido às más condições de conservação dos artefatos e à situação climática na floresta tropical, onde utensílios feitos de materiais orgânicos só se conservam em casos excepcionais. Assim, para as tábuas usadas para inalação de drogas dos índios Maué e Mura ${ }^{58}$ foram encontrados exemplares quase idênticos provenientes de sítios arqueológicos das regiões secas do norte da Argentina e do Chile. A grande maioria dos dados etnográficos evidencia que a produção e o uso de drogas alucinógenas inaláveis, independente de sua espécie, tinham finalidades relacionadas à religiosidade. Além de sua utilização em ritos de iniciação, elas estão correlacionadas com a magia e a invocação de espíritos e seres supra-humanos.

Mas, ao lado da utilização sacra, também conhecem-se usos profanos. No Rio Purus, os índios Catauish davam aos cães, como estimulante para a caça, "pó de paricá", uma droga inalável disseminada no Amazonas. ${ }^{59}$

\section{ORIGEM DA INVENTIVIDADE INDÍGENA}

Como os indígenas terão desenvolvido seus processos transformativos? Como chegaram a ter suas ideias? Estas perguntas, enganosamente simples, suscitaram respostas rápidas e precipitadas demais, para as quais refletiu-se espantosamente pouco, justamente por acreditar-se que os indígenas descobriam as coisas por tentativa e erro.

Ainda que pareça concludente, o método baseado na tentativa e erro dificilmente é suficiente para explicar processos tão sofisticados quanto os descritos acima. Mesmo que se trate "apenas" da descoberta de substâncias naturais ativas, um procedimento baseado em tentativa e erro é improvável, pois as plantas não contêm tais substâncias o tempo todo, nem em todas as partes, nem em todas as regiões. Deve haver um método de investigação indígena que até agora não foi pesquisado e sobre a qual só podemos especular.

A observação de animais e a subsequente imitação poderiam oferecer um ponto de referência. ${ }^{60}$ Foi demonstrado muitas vezes que povos ágrafos observam a natureza de modo mais preciso e intensivo do que podemos imaginar. ${ }^{61}$ Não deixa de ser plausível, portanto, que muitas de suas descobertas tenham ocorrido dessa maneira, inclusive, sendo abordadas em seus mitos. Assim, os índios Arawak do Suriname contam, a respeito da invenção da prensa tipiti, que ela foi desenvolvida quando o primeiro homem Arawak observou uma serpente que estava engolindo sua presa. Com base nisso, ele inventou o objeto baseando-se nos movimentos do corpo da serpente para criar o trançado do tipiti.

Outra explicação possível é a teoria que se fundamenta na transferência de práticas de uma área funcional para outra. Isto é conhecido no âmbito da tecnologia mecânica: povos que conhecem a roda passam a conhecer também, em pouco tempo, o torno de oleiro. ${ }^{62}$ De modo semelhante, na tecnologia química, um procedimento que se comprove eficaz na produção de alimentos, por exemplo, pode ser transferido para a produção de corantes ou fibras. A fermentação sob condições de temperatura controlada também exemplifica este processo ao servir para a preparação de alimentos, para o desenvenenamento e para a produção de corantes ou materiais.

\section{PROPRIEDADE INTELECTUAL}

Tendo em vista a importância econômica que as descobertas e invenções dos índios da Amazônia possuem, é de se perguntar se eles participaram de alguma forma da divisão dos lucros obtidos por empresas e indústrias que se beneficiaram de suas descobertas particularmente a Alemanha, que dispõe, desde o século 19, de uma eficiente indústria de alcaloides. ${ }^{63}$

Ora, nos períodos em que os europeus contrabandearam as mais importantes descobertas realizadas pelos ameríndios, já havia, na Europa, os primórdios de um direito de propriedade intelectual baseado na aquisição de patente. Mas naquela época, ainda não se discutia sobre como se deveria lidar com o conhecimento tradicional.

Apenas recentemente pode-se observar a preocupação em definir as regras para lidar com o conhecimento tradicional através da criação da Organização Mundial de Propriedade Intelectual (OMPI) - organização especial da ONU com sede em Genebra. A partir dos princípios gerais da propriedade intelectual, são elaborados princípios para o acesso ao conhecimento tradicional (WiPo Booklet, 2) ${ }^{64}$ como o Consentimento Prévio e Informado, segundo o qual informantes que disponham de conhecimento tradicional precisam concordar previamente antes de passarem seu conhecimento adiante. Outro princípio reconhecido pela OMPI é o equitable benefit-sharing [repartição equitativa dos benefícios]. Ele prevê que as pessoas que tenham disponibilizado conhecimento tradicional também devem participar adequadamente nos ganhos comerciais ou outras vantagens, como resultados de pesquisas. Esses princípios também servem de base para a convenção sobre a biodiversidade de 1992, que regula o acesso a recursos genéticos e a respectiva compensação justa de vantagens.

Não se pode afirmar que algum desses princípios tenha sido observado pelos europeus que, no século 19 ou início do século 20, levaram consigo conhecimento indígena sobre substâncias ativas, incluindo amostras dessas substâncias ou exemplares das plantas para a Europa ou para a América do Norte. Atualmente, esses princípios foram inseridos, em parte, nos ordenamentos jurídicos de países sul-americanos, particularmente do Brasil.

A partir da perspectiva atual, dificilmente se poderá fazer uma acusação às pessoas que viajaram naquela época. Além disso, substâncias ativas ou procedimentos quase nunca foram simplesmente copiados por europeus, mas, na maioria dos casos, desenvolvidos adicionalmente, seja isolando e transformando as substâncias, seja descobrindo usos inteiramente novos para elas - como a utilização da pilocarpina obtida a partir das folhas dos arbustos de jaborandi em doenças dos olhos ou na terapia do câncer. Ainda assim, causa desconforto a constatação de que pouquíssimas empresas, cujo faturamento, ainda hoje, baseia-se consideravelmente em descobertas ameríndias, preocupam-se em fazer com que aqueles povos participem de seu próprio sucesso científico, terapêutico ou econômico, sem falar de um engajamento mais substancial em prol da conservação dos espaços de vida daqueles povos.

\section{POR QUE OS HISTORIÓGRAFOS DA QUÍMICA SILENCIAM-SE SOBRE OS INDÍGENAS?}

Sem as contribuições dos indígenas da América do Sul, a farmacêutica, a medicina e também a química moderna teriam desenvolvimentos mais modestos - isso sem falarmos na agricultura e na culinária modernas. Sem a inventividade deles, não haveria, por exemplo, uma indústria da borracha e, a fortiori, tampouco uma indústria automobilística.

Por que nas muitas histórias da química e da tecnologia química não se encontram, em lugar algum, referências adequadas às contribuições vindas da América do Sul? Uma razão poderia ser a repercussão da imagem dos "canibais selvagens e ferozes" do período colonial. Por outro lado, aparentemente está ocorrendo uma tendência disseminada na historiografia, a saber, aquela de legitimar os próprios interesses através da própria produção historiográfica, 
enaltecendo a importância do seu espaço cultural. ${ }^{65,66} \mathrm{~A}$ historiografia, além de sua função ideológica, está a serviço de um determinado grupo de pessoas que a influenciam ou a constroem. ${ }^{67}$ Ela justifica uma situação de domínio existente, e isto não se aplica só à história política, mas também à historiografia das ciências. Por isso, uma história eurocêntrica da química utiliza-se das invenções indígenas sem preocupar-se em estabelecer qualquer tipo de contrapartida financeira ou reconhecimento intelectual.

\section{CONCLUSÃO}

Neste ensaio, pretendemos mostrar que, particularmente na área das práticas químicas, a inventividade e a inteligência técnica dos povos indígenas da América do Sul eram, e ainda são, consideráveis, sendo responsáveis por invenções das quais, até hoje, milhões de pessoas e instituições se beneficiam no mundo ocidental. Procuramos demonstrar essas afirmações a partir de alguns exemplos no âmbito das práticas químicas e dos procedimentos bioquímicos da transformação de substâncias que eram desconhecidos na Europa. A capacidade dos índios sul-americanos de obter substâncias e transformá-las deliberadamente é exposta a partir da produção de venenos, como o curare, ou também do desenvenenamento de plantas, como na produção de farinha de mandioca. Também foram mencionados outros procedimentos com múltiplas etapas visando à transformação deliberada de substâncias e à descoberta e utilização de substâncias naturais altamente ativas por parte de povos indígenas da Amazônia, como a borracha, por exemplo, mas também drogas psicoativas.

\section{AGRADECIMENTOS}

Os autores agradecem a Julia Fendt e Michael Schweiger pela ajuda na procura das referências bibliográficas, ao Dr. Guilherme Galhegos Felippe, Filipi Pompeu, a Luís Marcos Sander pelas traduções, sugestões e correções de uma das versões do texto. Muito obrigado ao diretor da Stadt und Staatsbibliothek Augsburg, Dr. Helmut Gier, pela gentileza de autorizar a consulta e a cópia de alguns documentos originais usados para compor este ensaio. Nossos agradecimentos vão também aos três avaliadores anônimos que com sua leitura crítica e minuciosa, contribuíram consideravelmente para melhorar este ensaio. A pesquisa relacionada à elaboração deste texto foi possível graças a uma Bolsa de Produtividade concedida pelo CNPq (2013-2015).

\section{REFERÊNCIAS}

1. Temáticas relacionadas foram apresentadas pelos autores nas seguintes publicações: Soentgen, J.; Hilbert, K.; Chem. Unserer Zeit 2012, 46, 322 e em Soentgen, J.; Hilbert, K.; Tópicos 2013, 52, 26.

2. Kopp, H.; Geschichte der Chemie, Friedrich Vieweg und Sohn: Braunschweig, 1843, 1, 19.

3. Needham, J.; Science and Civilization in China; Needham, J., ed.; Cambridge University Press: Cambridge, 1974-2008, 5.

4. Ray, P. C.; A History of Hindu Chemistry. From the Earliest Times to the Middle of the Sixteenth Century A.D.; Williams and Norgate: Calcutta, London, 1904, v. 1, 1909, v. 2.

5. Chakraborty, P.; The Indian Economic and Social History Review 2000, $37,185$.

6. Filgueiras, C. A. L.; Origens da Química no Brasil, Editora da UNICAMP: Campinas, 2015, pp. 35-37.

7. Staden, H.; Wahrhafftige Historia und Beschreibung eyner Landtschafft der Wilden/Nacketen/Grimmigen Menschenfresser Leuthen/in der Newen Welt America gelegen, Andres Kolben: Marpurg (Marburg), 1557.

8. Metcalf, A.; e-Journal of Portuguese History 2009, 7, 1.
9. Kohlhepp, G.; Das Bild Brasiliens im Lichte deutscher Forschungsreisender des 19. und der ersten Hälfte des 20. Jahrhunderts, Martius-Staden-Jahrbuch 2006, 53, 216.

10. Botting, D.; Humboldt and the Cosmos, Sphere Books: London, 1973.

11. Nordenskiöld, E.; The Journal of the Royal Anthropological Institute of Great Britain and Ireland 1929, 59, 273.

12. Silva, F. A.; Tese de Doutorado, Faculdade de Filosofia e Ciências Humanas da Universidade de São Paulo, São Paulo, Brasil, 2000.

13. Nepstad, D. C.; Stickler, C. M.; Soares-Filho, B.; Merry, F.; Philos. Trans. R. Soc., B 2008, 363, 1737.

14. Colinvaux, P.; Amazon Expedition. My Quest for the Ice-Age Equator. Yale University Press: New Haven, London, 2007.

15. Harborne, J. B.; Ökologische Biochemie. Eine Einführung, Spektrum Akademischer Verlag: Heidelberg, Berlin, Oxford, 1995.

16. Instituto Socioambiental: Almanaque Brasil Socioambiental, São Paulo, Brasília 2008, 84.

17. Cunha, M.; História dos índios no Brasil, Companhia das Letras: São Paulo, 1992.

18. Hilbert, K.; Estudos Ibero-Americanos - PUCRS 1998, 24, 291.

19. Roosevelt, A. C.; Lima da Costa, M.; Lopes Machado, C.; Michab, M.; Mercier, N.; Valladas, H.; Feathers, J.; Barnett, W.; Imazio da Silveira, M.; Henderson, A.; Sliva, J.; Chernoff, B.; Reese, D. S.; Holman, J. A.; Toth, N.; Schick, K.; Science 1996, 272, 373.

20. Politis, G.; Nukak, Instituto Amazónico de Investigaciones Científicas SINCHI: Bogotá, 1996.

21. Denevan, W. M.; Cultivated Landscapes of Native Amazonia and the Andes, Oxford University Press: Oxford, 2005.

22. Klein, U. In A Historical Ontology of Material Substances: c.17001830, Stuff: The Nature of Chemical Substances; Ruthenberg, K.; Brakel, J. v., eds.; Könighausen und Neumann: Würzburg, 2008, pp. 21-44.

23. Soentgen, J.; Stuff: A Phenomenological Definition, Stuff: The Nature of Chemical Substances; Ruthenberg, K.; Brakel, J. v., eds.; Könighausen und Neumann: Würzburg, 2008, 71-92.

24. Geertz, C. In Nova Luz, Sobre a Antropologia; Jorge Zahar: Rio de Janeiro, 2001.

25. de Anglería P. M.; Décadas del Nuevo Mundo, Editorial Bajel: Buenos Aires, 1944.

26. de Carvajal, G.; Relación del nuevo descubrimiento del famoso Río Grande que descubrió por muy gran ventura el Capitán Francisco de Orellana, Ministerio de Educación: Quito, 1942.

27. Freise, F. W.; Pharm. Ztg. 1936, 81, 818.

28. Humboldt, A. v.; Relation historique du voyage aux régions équinoxiales du Nouveau Continent, Premiére partie, Tome Second, Paris, 1819. Reedição: Beck, H.; Die Forschungsreise in den Tropen Amerikas; Wissenschaftliche Buchgesellschaft: Darmstadt, 1997.

29. Karrer, P.; Schmid, H.; Angew. Chem. 1955, 14-15, 361.

30. Warburg, O.; Die Pflanzenwelt. Zweiter Band: Dikothyledonen. Vielfrüchtler (Polycarpicae) bis Kaktusartige Gewächse (Cactales), Bibliographisches Institut: Leipzig, 1923 (1916).

31. Johns, T.; The Origins of Human Diet and Medicine. Chemical Ecology, The University of Arizona Press: Tucson, Arizona, 1996 (1990).

32. Sioli, H.; Gelebtes, geliebtes Amazonien. Forschungsreisen im brasilianischen Regenwald zwischen 1940-1962; Kohlhepp, G., ed.; Pfeil Verlag: München, 2007.

33. Lancaster, P. A.; Ingram, J. S.; Lim, M. Y.; Coursey, D. G.; Econ. Bot. 1982, 36, 12 .

34. Mowat, L.; Cassava and Chicha. Bread and Beer of the Amazonian Indians; Shire Ethnography: Haverfordwest, 1989.

35. Etkin, N. L.; Edible Medicines. An Ethnopharmacology of Food, The University of Arizona Press: Tucson, 2007.

36. de Sousa, G. S.; Tratado descriptivo do Brasil: em 1587, Editora Nacional: São Paulo, 1938. 
37. Koch-Grünberg, T.; Zwei Jahre bei den Indianern Nordwest-Brasiliens, Strecker und Schröder: Stuttgart, 1923.

38. Sampaio, A. J.; A alimentação Sertaneja e do Interior da Amazônia. Onomastica da Alimentação Rural, Companhia Editora Nacional: São Paulo, 1944.

39. Suhrbier, M. B.; Die richtige Mischung. Der Weg der Koka durch die Objekte der Kultur (Tukano, Nordwestamazonien), Missio, Message und Museum. Festschrift für Josef Franz Thiel zum 70. Geburtstag, Lembeck, Frankfurt, 2003, pp. 125-138.

40. Plowman, T.; J. Ethnopharmacol. 1981, 3, 195.

41. Roth, K.; Streller, S.; Chem. Unserer Zeit 2012, 46, 228.

42. Kaufman, T. S.; Rúveda, E. A.; Angew. Chem. 2005, 117, 876.

43. Holmstedt, B.; Wassén, S. H.; Schultes, R. E. J.; Ethnopharmacol. 1979, 1,3 .

44. Hartmann, G.; Tese de Doutorado, Freie Universität, Berlin, 1958.

45. Durry, A.; Schiffer, T.; Kakao. Speise der Götter, Oekom Verlag: München, 2011, 7.

46. Glaser, B.; Woods, W. I., eds.; Amazonian Dark Earths: Explorations in Space and Time; Springer: Berlin, Heidelberg, 2004.

47. Heizer, R. F. In Venenos de pesca, SUMA, Etnológica Brasileira; Ribeiro, B.; Ribeiro, D., eds.; Vozes: Petrópolis, 1987, 1, pp. 95-99.

48. Pereira, N.; Panorama da alimentação indígena: Comidas, bebidas \& tóxicos na amazônia brasileira, Livraria São José: Rio de Janeiro, 1974.

49. Rätsch, C.; Enzyklopädie der psychoaktiven Pflanzen. Botanik, Ethnopharmakologie und Anwendungen, AT Verlag: Aarau, 2007.

50. Rivier, L.; J. Ethnopharmacol. 1981, 3, 313.

51. Serrano, A.; Revista Americana 1941, 15, Buenos Aires.

52. Wassén, S. H.; Ethnographische Zeitschrift 1971, 1, 47.

53. Zerries, O.; Unter Indianern Brasiliens. Sammlung Spix und Martius 1817-1820, Sammlung aus dem Staatlichen Museum für Völkerkunde; Pinguin: Innsbruck, 1980, 1.

54. Cooper, J. In Handbook of South American Indians; Steward, J. H., ed.; Smithsonian Institution: Washington D. C., 1948, 5, pp. 525-558.
55. Prance, G. Etnobotânica de algumas tribos Amazônicas, SUMA, Etnológica Brasileira, Ribeiro, B., Ribeiro, D., eds.; Vozes: Petrópolis, 1987, 1, pp. 119-154.

56. Hartmann, G.; In Rausch und Realität. Drogen im Kulturvergleich, Materialien zu einer Ausstellung des Rautenstrauch-Joest Museum für Völkerkunde der Stadt Köln, 7. August bis 11. Oktober 1981, 1, pp. 224-235.

57. Rodrigues Ferreira, A.; Revista do Instituto Histórico e Geográfico Brasileiro. 1885-88, 48, 234; 49, 123-288; 50, 11-141; 51, 5-104.

58. Nimuendajú-Unkel, K. In Handbook of South American Indians; Steward, J. H., ed.; Bureau of American Ethnology, Bul.: Washington D. C., 1948, 143, pp. 245-254.

59. Spruce, R.; Notes of a Botanist on the Amazon and Andes, Macmillan: London, 1874.

60. Newton, P.; Wolfe, N.; Br. Med. 1992, 305, 1517.

61. Totzke, R.; Buchstaben-Folgen. Schriftlichkeit, Wissenschaft und Heideggers Kritik an der Wissenschaftsideologie. Velbrück Wissenschaft: Weilerswist, 2004, 367.

62. Leroi-Gourhan, A.; Milieu et technique, Albin Michel: Paris, 2002 (1945/1973), 344-345.

63. de Ridder, M.; Heroin. Vom Arzneimittel zur Droge, Campus: Frankfurt am Main, 2000.

64. World Intellectual Property Organization (WiPo), Intellectual Property and Traditional Knowledge, Booklet Number 2, Genf (o.J.).

65. Cronon, W.; Journal of American History; 1992, 78, 1347.

66. Pankau, J. G. Stichwort Erzählung, Historisches Wörterbuch der Rhetorik; Ueding, G., ed.; Max Niemeyer Verlag: Tübingen, 1994, 2, pp. 1432-1438.

67. Harth, D.; Artikel Geschichtsschreibung, Historisches Wörterbuch der Rhetorik; Ueding, G., ed.; Max Niemeyer Verlag: Tübingen, 1994, 1, pp. 832-870, 833-837. 